\title{
13th FINA World Championships: Analysis of swimsuits used by elite male swimmers
}

HENRIQUE P. NEIVA ${ }^{1,2}$, JOÃO PAULO VILAS-BOAS ${ }^{3,4}$, TIAGO M. BARBOSA ${ }^{2,5}$, ANTÓNIO J. SILVA ${ }^{2,6}$, DANIEL A. MARINHO1,2

1 University of Beira Interior, Department of Sport Sciences, UBI, Covilhã, Portugal

${ }^{2}$ Research Centre in Sports, Health and Human Development, CIDESD, Portugal

${ }^{3}$ University of Porto. Faculty of Sport/Biomechanics Lab, FADE-UP, Porto, Portugal

${ }^{4}$ Centre of Research, Education, Innovation and Intervention in Sport, CIFI2D, Portugal

${ }^{5}$ Polytechnic Institute of Bragança. Department of Sport Sciences, IPB, Bragança, Portugal

${ }^{6}$ University of Trás-os-Montes and Alto Douro/ Department of Sport, Exercise and Health, UTAD, Vila Real, Portugal

\begin{abstract}
Neiva HP, Vilas-Boas JP, Barbosa TM, Silva AJ, Marinho DA. 13th FINA World Championships: Analysis of swimsuits used by elite male swimmers. J. Hum. Sport Exerc. Vol. 6, No. 1, pp. 87-93, 2011. The purpose of this study was to describe the distribution of different swimsuits models used by male swimmers during all the finals at the 13th FINA World Championships, being held at Rome in 2009. Simultaneously, it was intended to verify the distribution of the different swimsuits used along the distances of the freestyle finals, and thus to understand the preferences of the top-level swimmers. It were used the results databases from the 13th FINA World Championships, in Rome 2009. Only the male swimmers participating at the finals were analyzed, for a total number of 17 individual swimming events. The wear swimsuit by each swimmer in a given event was observed from video recorded of the television broadcast. Male swimmers participating in the finals limited their choice to seven types of commercial swimsuits, of four different sports brands. Jaked01 Full ${ }^{\circledR}$ was the most used (47.07\%), followed by the Powerskin X-Glide Full ${ }^{\circledR}(34.56 \%)$, the Powerskin X-Glide Pants ${ }^{\circledR}(7.35 \%)$ and the LZR Racer Full ${ }^{\circledR}(5.15 \%)$. In freestyle swimming events most of the male swimmers choose to wear full body swimsuits. Jaked01 Full ${ }^{\circledR}$ was predominant in the $50 \mathrm{~m}$ event, with $62.50 \%$ of swimmers choices. This value decreases to $25.00 \%$ when analyzing $100 \mathrm{~m}$ event, and remained similar over the longer distances swum. The Powerskin X-Glide Full ${ }^{\circledR}$ was used for $37.50 \%$ of the swimmers in $50 \mathrm{~m}$ swimming event, and it increases to $62.50 \%$ for the $100 \mathrm{~m}$ freestyle. These results seem to demonstrate that swimmers have preferences for full swimsuits, and for these two swimsuits, the Powerskin X-Glide Full ${ }^{\circledR}$ and the Jaked01 Full ${ }^{\circledR}$. Key words: SWIMMING, DRAG, POLYURETHANE, TECHNIQUES, DISTANCES, TECHNOLOGY.
\end{abstract}

Corresponding author. Departamento de Ciências do Desporto. Universidade da Beira Interior. Rua Marquês D’Ávila e Bolama. 6201-001 Covilhã. Portugal

E-mail:dmarinho@ubi.pt

Submitted for publication October 2010.

Accepted for publication February 2011.

JOURNAL OF HUMAN SPORT \& EXERCISE ISSN 1988-5202

(c) Faculty of Education. University of Alicante

doi:10.4100/jhse.2011.61.10 


\section{INTRODUCTION}

The popularization of polyurethane swimsuits has got a large media and sports attention around the pools in the past couple of seasons. In the World Championships held in Rome, in 2009, swimmers used swimsuits produced partially or entirely with industrial polymers, and 43 world records were broken in such time frame. This record rush never happened before, and these "rubber" swimsuits could be part of the explanation for this performance enhancement. The manufactures claimed these suits have features such as ultra-light weight, water repellence, muscles oscillation and skin vibration reduction by compression the body. However, little scientific evidence was reported in main literature about such relationship.

Even so, to swim faster it is needed to increase the thrust and reduce drag, which it seems, has been achieved with the new generation of polyurethane swimsuits (Marinho et al., 2009). A better body position, without losing the movement range of motion and the reducing of water resistance due to a decrease of the frontal surface area are believed to be some of the reasons why swimmers go faster wearing these swimsuits (Kainuma et al., 2009). Some authors suggested that the use of full body suits could reduce total drag (pressure, wave and friction) (Toussaint et al., 2002; Pendergast et al., 2006). Friction drag seems to be largely influenced by the use of swimsuits, however it represents only $10-15 \%$ of total drag (Mollendorf et al., 2004; Bixler et al., 2007). Added to that, these new swimsuits are very thigh fitting, thus compacting the body, eliminating air pockets (Mountjoy, et al., 2009) and improving swimming coordination (Chollet et al., 2010). Knowing that buoyancy could be a factor that influences performance (McLean and Hinrichs, 2000), it seems possible that the new swimsuits can influence this parameter. Cortesi et al. (2010) have showed that average hydrostatic lift was found to be smaller when the swimmers wear polyurethane swimsuits, mainly because they reduce body volume without changing body mass. This could be related to the observed reduction in the chest and abdominal circumferences, suggesting that the improvement in performance is not related with better static buoyancy, even if these swimsuits make indeed the difference in dynamic conditions.

An alternative mechanism responsible for the function of the swimsuits is proposed by Kainuma et al. (2009). It is suggested that the suits are so tight that the blood circulation is suppressed. Anaerobic glycolysis system is stimulated but aerobic mitochondrial respiration system is suppressed, favoring short distance swimming events due to the obtained instantaneous force in white fibers of the skeletal muscles (Kainuma et al., 2009).

As these new swimsuits are made from Neoprene rubber, probably they present beneficial characteristics similar to wetsuits, used by thriathletes: a more horizontal position because of the added buoyancy (Toussaint et al., 1989; Chatard et al., 1995; Chatard et al., 1996), reduced drag force by the smooth surface provided (Toussaint et al., 1989; Chatard et al., 1995) and reduction in energy consumption (Tomikawa et al., 2008). Although the similarities between the polyurethane swimsuits and the wetsuits, it is important to consider that the swimsuits are thinner and these benefits could not be exactly the same, especially considering that the wetsuits (made of neoprene fibers) allow to decrease the density of the lower limbs of the swimmer due to the increasing on the thickness of the suit on those segments.

As it could be noted, the proposed mechanisms for the enhancement of swimming times by the swimsuits are multiple and controversy. The increasing range of swimsuits available, developed after the launch of the first new type of swimsuits in 2008, allowed swimmers to have more choice to improve performance, and contributing to this controversy around the polyurethane swimsuits. 
The present study intended to verify the distribution of the different swimsuits used in different techniques, as well as to verify its distribution for the different distances in freestyle events, in order to understand the preferences of top-level swimmers.

\section{MATERIAL AND METHODS}

\section{Sample and procedures}

Results databases from the 13th FINA World Championships, in Rome 2009 were used. Only male swimmers participating in the finals were analyzed. An overall of 17 individual swimming finals were observed. Each final had 8 swimmers, which makes 136 swimsuits analyzed in the total sample. The wearing swimsuits were observed from video recorded of the television broadcast. This data was analyzed considering different swimming techniques (i.e., freestyle, backstroke, breaststroke, butterfly strokes) and different distances in freestyle events (i.e., 50 m, 100 m, 200 m, 400 m, 800 m and 1500 m).

Swimming suits were identified: (i) by the brand displayed on the swimming suit; (ii) by the main characteristics of each swimming suit (such as, design, color, sewing process, etc). Broadcasted images were analyzed by a swimming expert that has a graduation course in Sport Science, is a national level coach and a former elite swimmer, and by a Portuguese swimmer present in the 13th FINA World Championships.

\section{Statistics}

The data collected was analyzed by standard statistical methods, calculating relative frequencies (number and percentages) and its distribution. Statistical graphics were also made in order to better understand swimsuits distribution. Analysis was made for each swimming event and for the swimmers reaching a podium position.

\section{RESULTS}

Male swimmers participating in the finals limited their choice to seven types of swimsuits, of four different sports brands. Table 1 reports, for the total sample, the swimsuits models used by the swimmers and the number of podiums reached by the swimmers according to the different swimsuits chosen, and its corresponding percentage.

Table 1. Frequency analysis, number ( $n$ ) and percentage (\%), of swimsuits chosen by the swimmers and podiums achieved wearing each one of the swimsuit analyzed.

\begin{tabular}{lcccc}
\hline \multirow{2}{*}{ Swimsuit } & \multicolumn{2}{c}{ Swimmer choice } & \multicolumn{2}{c}{ Podiums } \\
& $\mathrm{n}$ & $\%$ & $\mathrm{n}$ & $\%$ \\
\hline Jaked01 Full $^{\circledR}$ & 64 & 47.06 & 15 & 29.41 \\
Powerskin X- Glide Full $^{\circledR}$ & 47 & 34.56 & 21 & 41.18 \\
Powerskin X- Glide Pants $^{\circledR}$ & 10 & 7.35 & 4 & 7.84 \\
LZR Racer Full $^{\circledR}$ & 7 & 5.15 & 5 & 9.80 \\
Jaked01 Pants $^{\circledR}$ & 4 & 2.94 & 3 & 5.88 \\
Hydrofoil Full $^{\circledR}$ & 2 & 1.47 & 1 & 1.96 \\
LZR Racer Pants $^{\circledR}$ & 1 & 0.74 & 1 & 1.96 \\
Unknown & 1 & 0.74 & 1 & 1.96 \\
\hline Total & 136 & 100 & 51 & 100
\end{tabular}


Table 2 presents the frequency distribution of the several swimsuits used by the swimmers, in the different swimming techniques.

Table 2. Percentage (\%) of wearing swimsuits in the different technique swimming events.

\begin{tabular}{|c|c|c|c|c|c|}
\hline Swimsuit & $\begin{array}{c}\text { Freestyle } \\
\mathrm{n}(\%)\end{array}$ & $\begin{array}{c}\text { Butterfly } \\
n(\%)\end{array}$ & $\begin{array}{c}\text { Backstroke } \\
\mathrm{n}(\%)\end{array}$ & $\begin{array}{c}\text { Breaststroke } \\
n(\%)\end{array}$ & $\begin{array}{c}\text { Medley } \\
\mathrm{n}(\%)\end{array}$ \\
\hline Powerskin X-Glide Full ${ }^{\circledR}$ & 56.25 & 25.00 & 20.83 & 20.83 & 25.00 \\
\hline Jaked01 Full ${ }^{\circledR}$ & 29.17 & 58.33 & 33.33 & 79.17 & 56.25 \\
\hline LZR Racer Full ${ }^{\circledR}$ & 10.42 & 4.17 & & & 6.25 \\
\hline Hydrofoil Full ${ }^{\circledR}$ & & & 8.33 & & \\
\hline Powerskin X-Glide Pants ${ }^{\circledR}$ & & 4.17 & 33.33 & & 6.25 \\
\hline Jaked01 Pants ${ }^{\circledR}$ & 2.08 & 4.17 & 4.17 & & 6.25 \\
\hline LZR Racer Pants ${ }^{\circledR}$ & & 4.17 & & & \\
\hline Unknown & 2.08 & & & & \\
\hline Total & 100 & 100 & 100 & 100 & 100 \\
\hline
\end{tabular}

Regarding the freestyle swimming events, the distribution of the swimmers choices according to the swimsuit brand and type, depending on distance swimming, is represented in Figure 1.

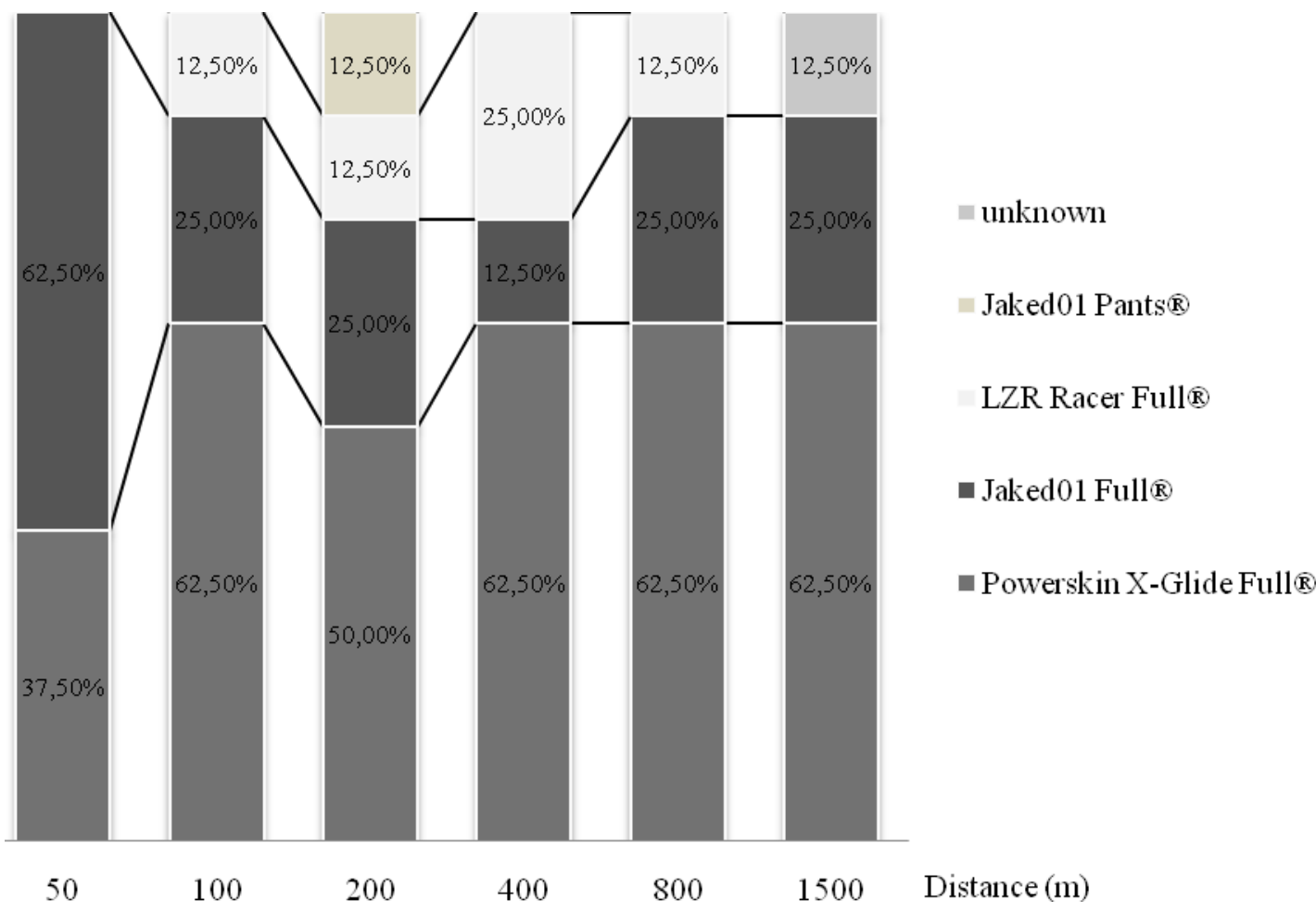

Figure 1. Distribution of the swimsuits, in percentage (\%), by different distances of freestyle swimming events. 


\section{DISCUSSION}

The main aim of this study was to verify the distribution of the different swimsuits used in different techniques, as well as to verify its distribution for the different distances in freestyle events, in order to better understand the preferences of top level swimmers. Main data was that male swimmers participating in the finals of the 13th FINA World Championships limited their choice to seven types of swimsuits, of four different sports brands. Jaked01 Full ${ }^{\circledR}$ was the most used, followed by the Powerskin X-Glide Full ${ }^{\circledR}$, both being used by $82 \%$ of the swimmers, suggesting a clear preference for the full type swimsuits.

Historically, Fastskin® swimsuits emerged slowly in the early 2000s, with the first generation conceived to reduce hydrodynamic drag. After the Sydney Olympics, the second generation showed further advances, with new materials like polyurethane (Chollet et al, 2010). After the launch of the first new type of swimsuits in 2008, with LZR Racer Full囚, several companies followed with other versions, increasing the range of swimsuits available for the swimmers. Berthelot et al. (2010) investigated the recent evolutions of the best performers over the 1990 - 2009 period and demonstrates that three bursts of performances occurred in 2000, 2008 and 2009, which corresponds to the introduction of the three generations of swimsuits: Fastskin $囚$, LZR Racer Full and the full polyurethane swimsuits.

However, recently FINA has decided that swimmers are not allowed to wear full-body, full-legs or polyurethane suits (starting January 2010). Even with the prohibition of the use of the polyurethane swimsuits nowadays, in 2008 and in 2009 several world records were established in major international swimming competitions, and it seems important to better understand this so-called techno suits and the correspondent "techno doping" effect. Although this evolution in the swimsuits and improvements of swimmers performances, the mechanisms of this improvement by the use of polyurethane swimsuits are not well known and studies regarding this matter are very scarce.

The results of the present study demonstrate that swimmers clearly preferred to use full swimsuits covering both the torso and legs, probably contributing for a extended body compression and a higher drag decrease (Mollendorf et al., 2004). Backstroke is the only swimming technique that pants were used in the same percentage, and this could be because a great part of the torso is not under water during all distance of the swimming event. It was interesting to note that $41.18 \%$ of the swimmers wearing Powerskin X-Glide Full ${ }^{\circledR}$ reached the podium, against the $29.41 \%$ with Jaked01 Full ${ }^{\circledR}$. It can be speculated that the Powerskin X-Glide Full ${ }^{\circledR}$ might be the most efficient when regarding medals achievement. However, hydrodynamic researched could be done comparing several swim suits models to highlight this issue.

Regarding the swimsuits chosen by the swimmers to perform the different distances of freestyle swimming events, Jaked01 Full ${ }^{\circledR}$ was predominant in the shorter distance $(50 \mathrm{~m})$ with $62.50 \%$ of swimmers choices. This value decreases to about half of choices when analyzing $100 \mathrm{~m}$ swimming event, and remained similar over the distances swum. However, the Powerskin X-Glide Full ${ }^{\circledR}$ is used for $37.50 \%$ of the swimmers in 50 $\mathrm{m}$ swimming event, and it increases twice for the $100 \mathrm{~m}$ freestyle. This value remained similar over distances up to $1500 \mathrm{~m}$. The maximum value reached by the LZR Racer Full ${ }^{\circledR}$ was $25.00 \%$ of use, in the $400 \mathrm{~m}$, being less used in the other swimming events, even reaching zero values in $50 \mathrm{~m}$ and in $1500 \mathrm{~m}$ events. Although Kainuma et al. (2009) have suggested that suits stimulates anaerobic glycolysis system favoring short distance swimming events, these results demonstrates that the swimmers used the tight swimsuits no matter the distances of the swimming event. The literature is very scarce in this matter, and more research is needed to better understand physiological responses when using swimsuits. Moreover, 
these results cannot establish a clear preference of the swimmers, according to the distances of swimming. It is clear that the full swimsuits are preferred, both in $50 \mathrm{~m}$, as in the $1500 \mathrm{~m}$.

\section{CONCLUSIONS}

This study focuses on the best swimmers of the world, who attended the finals of the 2009 World Championship, and this certainly implies that they have experienced several types of swimsuits and at that moment they chose to swim with the one that they think is better for their greater performance. Further investigations could be useful to better understand the swimmers choices, attempting to understand the preference for the two swimsuits: the Powerskin X-Glide Full ${ }^{\circledR}$ and the Jaked01 Full ${ }^{\circledR}$. To our knowledge, the present study was the first to analyze the preferences of this last generation of swimsuits by the swimmers, and to better understand this issue, further investigation could be done to know the mechanisms of performance related do the polyurethane swimsuits.

In summary, the current data seems to demonstrate that swimmers preferred full swimsuits, and two types of swimsuits, the Powerskin X-Glide Full ${ }^{\circledR}$ and the Jaked01 Full ${ }^{\circledR}$, seemed to be the main choice of the elite male swimmers.

\section{REFERENCES}

1. BERTHELOT G, LEN S, HELLARD P, TAFFLET M, HELOU NE, ESCOLANO S, GUILLAUME M, SCHAAL K, NASSIF H, DESGORCES FD, TOUSSAINT JF. Technology \& swimming: 3 steps beyond physiology. Materials Today. 2010; 11:46-51. doi:10.1016/S1369-7021(10)70203-0 [Back to text]

2. BIXLER B, PEASE D, FAIRHURST $F$. The accuracy of computational fluid dynamics analysis of the passive drag of a male swimmer. Sports Biomech. 2007; 6(1):81-98. [Abstract] [Back to text]

3. CHATARD JC, MILLET G. Effects of wetsuit use in swimming events. Sports Med. 1996; 22: 70-75. [Back to text]

4. CHATARD JC, SENEGAS X, SELLES M, DREANOT P, GEYSSANT A. Wet suit effect: a comparison between competitive swimmers and triathletes. Med Sci Sports Exerc. 1995; 27(4):580- 586. [Abstract] [Back to text]

5. CHOLLET D, CHAVALLARD F, SEIFERT L, LEMAÎTRE F. Do Fastskin Swimsuits Influence Coordination in Front Crawl Swimming and Glide? In: PL Kjendlie, RK Stallman,J Cabri (Eds). Biomechanics and Medicine in Swimming XI. Norwegian School of Sport Sciences: Oslo; 2010. 55-57. [Full Text] [Back to text]

6. CORTESI M, ZAMPARO P, TAM E, DA BOIT M, GATTA G. The Effect of Wearing a Synthetic Rubber Suit on Hydrostatic Lift and Lung Volume. In: PL Kjendlie, RK Stallman,J Cabri (Eds). Biomechanics and Medicine in Swimming XI. Norwegian School of Sport Sciences: Oslo; 2010. 57-59. [Full Text] [Back to text]

7. KAINUMA E, WATANABE M, TOMIYAMA-MIYAJI C, INOUE M, KUWANO Y, REN H, ABO T. Proposal of alternative mechanism responsible for the function of high-speed swimsuits. Biomed Res. 2009; 30(1):69-70. doi:10.2220/biomedres.30.69 [Back to text]

8. MARINHO DA, BARBOSA TM, KJENDLIE PL, VILAS-BOAS JP, ALVES FB, ROUBOA AI, SILVA AJ. Swimming simulation: a new tool for swimming research and practical applications. In: M Peters (Ed). Lecture Notes in Computational Science and Engineering. 2009; 72:33-61. doi:10.1007/978-3-64204466-3_2 [Back to text]

9. MCLEAN SP, HINRICHS RN. Buoyancy, gender, and swimming performance. J Appl Biomech. 2000; 16:248-63. [Abstract] [Back to text] 
10. MOLLENDORF JC, TERMIN II AC, OPPENHEIM E, PENDERGAAST DR. Effect of swim suit design on passive drag. Med. Sci. Sports Exerc. 2004; 36(6):1029-1035. [Full Text] [Back to text]

11. MOUNTJOY M, GORDON I, MCKEOWN J, CONSTANTINI N. Medical complications of an aquatic innovation. Br J Sports Med. 2009; 43:979-980. doi:10.1136/bjsm.2009.067215 [Back to text]

12. PENDERGAST DR, MOLLENDORF JC, CUVIELLO R, TERMIN II. Application of theoretical principles to swimsuit drag reduction. Sports Eng. 2006; 9:65-76. doi:10.1007/BF02844859 [Back to text]

13. TOMIKAWA M, SHIMOYAMA Y, NOMURA T. Factors related to the advantageous effects of wearing a wetsuit during swimming at different submaximal velocity in triathletes. J Sci Med Sport. 2008; 11:417-23. doi:10.1016/j.jsams.2007.02.005 [Back to text]

14. TOUSSAINT HM, BRUININK L, COSTER R, DE LOOZE M, VAN ROSSEM B, VAN VEENEN R, DE GROOT, G. Effect of a triathlon wetsuit on drag during swimming. Med Sci Sports Exerc. 1989; 21:325-28. [Abstract] [Back to text]

15. TOUSSAINT HM, TRUIJENS M, ELZINGA MJ, VAN DE VEN A, DE BEST H, DE GROOT G. Effect of a Fast-skin "body" suit on drag during front crawl swimming. Sports Biomech. 2002; 1(1):1-10. [Full Text] [Back to text] 